\title{
Acute Paraspinal Compartment Syndrome Related to Use of Proprietary Weight Loss Product, by a Patient with Sodium Channelopathy
}

\section{Jenny L Lauschke ${ }^{1,2}$ and Gabor Major ${ }^{1,3 *}$}

${ }^{1}$ Department of Rheumatology, Bone and Joint Centre Royal Newcastle Centre, John Hunter Hospital, Newcastle NSW, Australia ${ }^{2}$ Prince of Wales Hospital NSW, Australia

${ }^{3}$ Faculty of Medicine, University of Newcastle NSW Australia

\begin{abstract}
Paraspinal compartment syndrome is a rare cause of lower back pain that remains under-recognized and under-treated and which can result in prolonged and debilitating pain. We present the case of a young female with paramyotonia congenita due to sodium chanelopathy, who developed acute paraspinal compartment syndrome after ingestion of an ephedrine containing proprietary weight loss product. We highlight the challenges in diagnosis and management and review potential precipitating factors and mechanisms underlying the clinical features.
\end{abstract}

Keywords: Acute back pain; Compartment syndrome; Cluneal nerve; Rhabdomyolysis; Ephedrine; Paramyotonia congenita; Sodium channelopathy; SCN4A gene mutation

Abbreviations: CK: Creatinine Kinase; AST: Aspartate Aminotransferase, ALT: Alanine Aminotransferase; CRP: C Reactive Protein

\section{Introduction}

Acute compartment syndrome is a well described entity that can occur in any closed fibro-osseous space and is particularly common in the lower limb compartments. In the limbs a clearly defined set of clinical findings, comprising excessive pain on passive stretch, pallor, paraesthesia, loss of pulses and ultimately paralysis- allow for early detection and facilitate prompt investigation and treatment.

In contrast, acute compartment syndrome involving the paraspinal muscle is a rare cause of back pain where the classic signs and symptoms may be ill-defined, resulting in under recognition and treatment. While diagnostic criteria based on the shared features of earlier case reports have been proposed [1], the syndrome is essentially heterogeneous in its presentation and much remains to be learned about aetiology and management.

In this report we present the case of a young female with paramyotonia congenita who sustained acute exertional spinal compartment syndrome following use of Xenadrine ${ }^{\bullet}$, a caffeine and ephedrine containing proprietary weight loss product.

\section{Case Report}

A 29-year old female presented to the emergency department of her local hospital with sudden onset severe lower back pain following moderately strenuous exercise using a treadmill and weight lifting. The pain was predominantly in the left lumbar region and buttocks radiating to the left groin, anterior thigh and tailbone and remained severe over the next 5 hours despite self-medication with paracetamol, naproxen and diazepam.

Examination revealed a distressed woman with paraspinal muscle tenderness, particularly on the left, which was aggravated by straight leg raise. Patchy paraesthesiae were noted over the lower back, buttocks and feet bilaterally.

Laboratory findings on admission showed myoglobinuria, raised creatinine kinase $(\mathrm{CK})$ of 23,900 U/L (1-125 U/L), aspartate aminotransferase (AST) $538 \mathrm{U} / \mathrm{L}$ (1-30 U/L), alanine aminotransferase (ALT) $151 \mathrm{U} / \mathrm{L}$ (1-30 U/L), and C-reactive protein (CRP) $12 \mathrm{U} / \mathrm{L}(<3.1$ $\mathrm{U} / \mathrm{L})$. White cell count, haemoglobin, electrolytes and creatinine were all within normal limits. A diagnosis of rhabdomyolysis was made. A lumbar spine MRI performed 2 days post incident showed swelling and homogenous signal increase in the T2-weighted images of the erector spinae muscle group consistent with left paraspinal muscle oedema (Figure 1A). All viral and infectious serology tests were negative.

The patient was managed conservatively in hospital with bed rest, intravenous fluids and opioid analgesia. The CK peaked on day 2 at $35,600 \mathrm{U} / \mathrm{L}$, gradually returning to normal afterwards and she was discharged home after 2 weeks.

4 weeks post-incident the patient returned to the same emergency department due to ongoing severe back pain and was transferred to our institution.

On further history the patient revealed that she attends the gym 4-5 times per week and had been using Xenadrine, a proprietary "thermogenic weight loss" product containing the herbs Ma Huang (ephedrine) and Guarana (caffeine), in the weeks preceding the incident. She reported minimal alcohol consumption and continued to characterise the exercise preceding the onset of her back pain

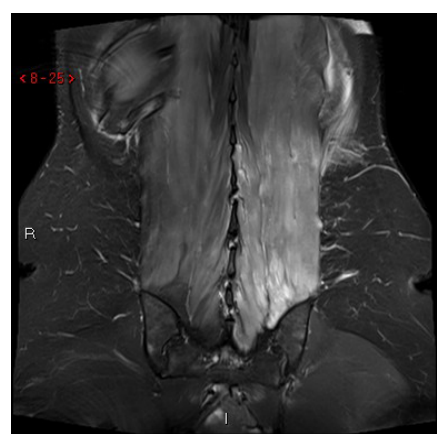

Figure 1(A): T2-weighted image at presentation.

*Corresponding author: Major G, Department of Rheumatology John Hunter Hospital, Lookout Rd New Lambton Heights NSW 2305 Australia, Tel: +61 2 49552300; Fax: +61 2 49223562; E-mail: gabor.major@hnehealth.nsw.gov.au

Received January 01, 2016; Accepted February 17, 2016; Published February 19, 2016

Citation: Lauschke JL, Major G (2016) Acute Paraspinal Compartment Syndrome Related to Use of Proprietary Weight Loss Product, by a Patient with Sodium Channelopathy. J Spine S7: 001.doi:10.4172/2165-7939.S7-001

Copyright: (c) 2016 Lauschke JL, et al. This is an open-access article distributed under the terms of the Creative Commons Attribution License, which permits unrestricted use, distribution, and reproduction in any medium, provided the original author and source are credited. 




Figure 1(B): T2-weighted image after 6 weeks.

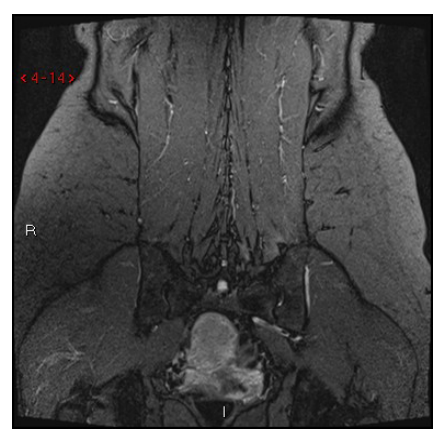

Figure 1(C): T2-weighted image after 6 months

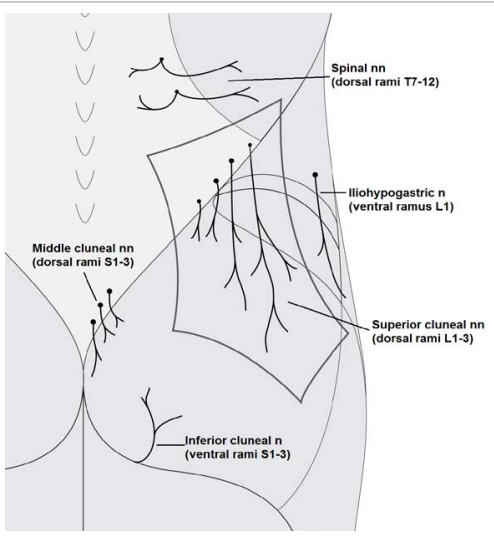

Figure 2: Cutaneous nerve innervation of the lumbar spine and buttocks by superior cluneal nerves. (area shows dermatomal innervation of superior cluneal nerves).

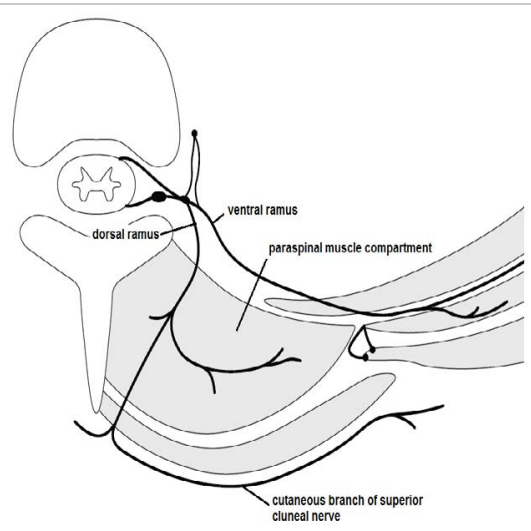

Figure 3: Path of the superior cluneal nerve through the paraspinal muscle compartment. as moderate. She described a prior history of often experiencing prolonged stiffness following exercise, as well as frequent cramping and said that she had previously been diagnosed with chronic compartment syndrome in her legs. She has a background medical history of benign joint hypermobility (EDS II) with frequent shoulder and hip dislocations, and paramyotonia congenita, subsequently shown to be a sodium channelopathy (mutation p.Val1589Met in exon 24 of the skeletal muscle sodium channel (SCN4A) gene).

Repeat physical examination revealed a young woman who maintained a guarded posture throughout examination. Lumbar paraspinal and left buttock firmness and tenderness were noted and a markedly decreased range of active and passive movements in lumbar spine and hip due to pain. She complained of persistent paraesthesiae over her lower back and buttocks with a burning radiation into the left thigh. It was furthermore noted that she had marked myotonia without any dystrophic features.

Laboratory investigations at the time of second presentation were all within normal limits. CK had normalized to $70 \mathrm{U} / \mathrm{L}$. A repeat MRI was essentially unchanged and showed persistence of left paraspinal muscle oedema of similar severity to the previous scan (Figure 1B). Bilateral spinal compartment pressures were measured using a Stryker manometer (Stryker Surgical Kalamazoo MI USA) pre- and post- mobilization [2] and were $7 \mathrm{~mm} \mathrm{Hg}$ pre and $18 \mathrm{~mm} \mathrm{Hg}$ post mobilisation on the left and 5 and $10 \mathrm{~mm} \mathrm{Hg}$ on the right [normal range $<10 \mathrm{mmHg}$. Surgical review concluded that invasive management was no longer indicated.

The patient was managed conservatively with oxycontin, amytriptiline, gabapentin and mexiletine, which provided partial relief of symptoms. A range of non-pharmacological measures were also tried and she reported most relief from heat packs, dynamic back taping and a lumbo-sacral corset. Hydrotherapy appeared to worsen the symptoms.

The patient underwent daily physiotherapy with gentle exercises and psychological support. She continued to have back pain on minimal exertion; required crutches to mobilise and home care assistance to manage her household. At the 6 month's follow-up the patient reported resolution of the symptoms. This was matched by significant improvement in the muscle oedema on MRI (Figure 1C). At the functional level she was able to perform most physical activities and had been able to return to work. The sensory impairment in the lumbar region and buttocks remained unchanged.

\section{Discussion}

Acute spinal compartment syndrome is rare cause of acute back pain, which has been reported in association with exercise such as surfing, skiing, and weightlifting [3-7].

Some of the patients report an increased amount of exercise prior to onset of the pain [7,8], but other case reports [3-5] show that acute spinal compartment syndrome may occur even with regular amount of exercise, as happened in this case, suggesting that other mechanisms may be responsible in those individuals.

Anatomical studies have confirmed that the erector spinae muscle group is enclosed within a well-defined fascial compartment $[9,10]$ albeit with variations in the completeness of compartmentalisation due to varying completeness of its fascial slings [11]. The superior cluneal nerve which derives from the dorsal rami of the first, second and third lumbar nerve roots runs through the compartment and is susceptible to compression damage [12] (Figures 2 and 3). 
The resultant sensory impairment which has been proposed as a diagnostic criterion, was also evident in our patient from the time of her initial presentation, and is an important alert about this rather rare entity and helps to distinguish it from other causes of acute back pain.

While the level of exercise undertaken by our patient was within her usual routine she was at additional risk of rhabdomyolysis by her use of an ephedrine containing weight loss product and her paramyotonia Rhabdomyolysis, a prominent feature in this case, can be both the cause and the consequence of compartment syndrome. Muscle bulk may increase by $20 \%$ after exertion [13] and direct myonecrosis can complicate overexertion [14,15]. Rhabdomyolysis can also be induced by a range of prescription medications, illicit drugs and dietary supplements [16-18], and while a reliable risk estimate of rhabdomyolysis with ephedrine containing weight loss products has not been established, concern based largely on case reports of a range of side effects have led to a call for regulation of these products [19]. Previous case reports of acute exertional compartment syndrome report use of isotretinoin and of supplements containing creatine, cocaine, testosterone and as in this case ephedrine $[6,8]$.

Rhabdomyolysis may also occur in patients with myotonic disorders such as this case $[20,21]$. In particular channelopathies predispose to malignant hyperthermia and rhabdomyolysis by way of abnormal excitability [22].

Case-based evidence suggests surgical intervention is the treatment of choice in acute compartment syndrome. Those patients who underwent surgery reported complete recovery after a few weeks. [47]. In contrast ongoing pains particularly on exertion were reported with conservative management $[3,8,9]$. Balancing the risks and benefits of surgery remains a difficult challenge, but a high index of suspicion may make the difference between a speedy resolution and an ongoing debilitating pain syndrome. The likelihood of surgical success in our case with presentation 4 weeks post incident remains unclear. Noninvasive treatment options have been reported [23], but have not been scientifically tested and may have other complications. Hyperbaric oxygen therapy has also been employed with good results [24] but was not available in our institution. Overall no single non-invasive treatment has matched the outcome of surgery [1].

\section{Conclusion}

In the appropriate clinical setting acute spinal compartment syndrome should be included in the differential list of causes of acute onset lumbar back pain. A high index of suspicion and awareness of the clinical features can prompt the relevant early investigation and treatment that may prevent prolonged pain and disability.

Sensory impairment in the region of the superior cluneal nerve may help distinguish acute paraspinal compartment syndrome from other causes of acute back pain.

\section{Acknowledgments}

The authors would like to acknowledge late Dr Lindsay Rowe for his help with the MRI images, Dr Jeff Blackie for neurophysiological studies and Dr Tracey Dudding for genetic analysis. We would also like to thank Mr Gabriel Weichert for his assistance with the diagrams.

\section{Conflict of Interest}

The other authors have no financial or proprietary interests to declare and there is no conflict of interest.

\section{References}

1. Nathan ST, Roberts CS, Deliberato D (2012) Lumbar paraspinal compartment syndrome. Int Orthop 36: 1221-1227.

2. Kjellmer I (1964) An indirect method for estimating tissue pressure with special reference to tissue pressure in muscle during exercise. Acta Physiol Scand 62: $31-40$.

3. DiFazio FA, Barth RA, Frymoyer JW (1991) Acute lumbar paraspinal compartment syndrome. A case report. J Bone Joint Surg Am 73: 1101-1103.

4. Kitajima I, Tachibana S, Hirota Y, Nakamichi K (2002) Acute paraspinal muscle compartment syndrome treated with surgical decompression: a case report. Am J Sports Med 30: 283-285.

5. Khan RJ, Fick DP, Guier CA, Menolascino MJ, Neal MC (2005) Acute paraspina compartment syndrome. A case report. J Bone Joint Surg Am 87: 1126-1128.

6. Minnema BJ, Neligan PC, Quraishi NA, Fehlings MG, Prakash S (2008) A case of occult compartment syndrome and nonresolving rhabdomyolysis. J Gen Intern Med 23: 871-874.

7. Paryavi E, Jobin CM, Ludwig SC, Zahiri H, Cushman J (2010) Acute exertional lumbar paraspinal compartment syndrome. Spine (Phila Pa 1976) 35: E15291533.

8. Wik L, Patterson JM, Oswald AE (2010) Exertional paraspinal muscle rhabdomyolysis and compartment syndrome: a cause of back pain not to be missed. Clin Rheumatol 29: 803-805

9. Carr D, Gilbertson L, Frymoyer J, Krag M, Pope M (1985) Lumbar paraspina compartment syndrome. A case report with physiologic and anatomic studies. Spine (Phila Pa 1976) 10: 816-820.

10. Peck D, Nicholls PJ, Beard C, Allen JR (1986) Are there compartment syndromes in some patients with idiopathic back pain? Spine (Phila Pa 1976) 11: $468-475$

11. Bogduk N, Macintosh JE (1984) The applied anatomy of the thoracolumbar fascia. Spine (Phila Pa 1976) 9: 164-170.

12. Lu J, Ebraheim NA, Huntoon M, Heck BE, Yeasting RA (1998) Anatomic considerations of superior cluneal nerve at posterior iliac crest region. Clin Orthop Relat Res : 224-228.

13. Styf $\mathrm{J}$ (1987) Pressure in the erector spinae muscle during exercise. Spine (Phila Pa 1976) 12: 675-679.

14. Line RL, Rust GS (1995) Acute exertional rhabdomyolysis. Am Fam Physician 52: 502-506.

15. Shi Y-LHX (2007) Exertional rhabdomyolysis. J Clin Rehabil Tissue Eng Res 11: $1123-1126$.

16. Curry SC, Chang D, Connor D (1989) Drug- and toxin-induced rhabdomyolysis Ann Emerg Med 18: 1068-1084.

17. Scroggie DA, Harris M, Sakai L (2000) Rhabdomyolysis associated with nutritional supplement use. J Clin Rheumatol 6: 328-332.

18. Dehoney S, Wellein M (2009) Rhabdomyolysis associated with the nutritional supplement Hydroxycut. Am J Health Syst Pharm 66: 142-148.

19. Fontanarosa PB, Rennie D, DeAngelis CD (2003) The need for regulation of dietary supplements-lessons from ephedra. JAMA 289: 1568-1570.

20. Jurkat-Rott K, Lerche H, Lehmann-Horn F (2002) Skeletal muscle channelopathies. J Neurol 249: 1493-1502.

21. Matthews E, Fialho D, Tan SV, Venance SL, Cannon SC, et al. (2010) The non-dystrophic myotonias: molecular pathogenesis, diagnosis and treatment Brain 133: 9-22.

22. Trip J, de Vries J, Drost G, Ginjaar HB, van Engelen BG, et al. (2009) Health status in non-dystrophic myotonias: close relation with pain and fatigue. $\mathrm{J}$ Neurol 256: 939-947

23. Hammer WI, Pfefer MT (2005) Treatment of a case of subacute lumbar compartment syndrome using the Graston technique. J Manipulative Physiol Ther 28: 199-204.

24. Karam MD, Amendola A, Mendoza-Lattes S (2010) Case report: successful treatment of acute exertional paraspinal compartment syndrome with hyperbaric oxygen therapy. lowa Orthop J 30: 188-90.

This article was originally published in a special issue, Spinal Cord Injury Rehabilitation handled by Editor(s). Dr. Alessandro Landi, University of Rome, Italy 